Pre-print; published in Geoderma as Müller K, Katuwal S, Young I, McLeod M, Moldrup P, de Jonge LW, Clothier B 2018. Characterising and linking X-ray CT derived macroporosity parameters to infiltration in soils with contrasting structures. Geoderma 313: 82-91.

https://doi.org/10.1016/j.geoderma.2017.10.020

\title{
Characterising and linking X-ray CT derived macroporosity parameters to infiltration in
}

\section{soils with contrasting structures}

Karin Müller ${ }^{a, *}$, Sheela Katuwal ${ }^{b}$, lain Young ${ }^{c}$, Malcolm McLeod ${ }^{d}$, Per Moldrup ${ }^{e}$, Lis Wollesen de Jonge ${ }^{b}$, Brent Clothier ${ }^{f}$

aThe New Zealand Institute for Plant \& Food Research Ltd., Private Bag 3230, Waikato Mail Centre, Hamilton 3240, New Zealand

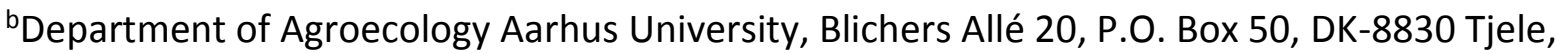
Denmark

'The The School of Life and Environmental Sciences, The University of Sydney, Sydney, NSW 2006, Australia

'Landcare Research, Private Bag 3127, Waikato Mail Centre, Hamilton, New Zealand

eDepartment of Civil Engineering, Aalborg University, Thomas Manns Vej 23, Aalborg $\varnothing$, 9200-Denmark

fThe New Zealand Institute for Plant \& Food Research Ltd., Fitzherbert Science Centre, Palmerston North, New Zealand

${ }^{*}$ Corresponding author. E-mail address: karin.mueller@plantandfood.co,nz (K. Müller). 


\section{Abstract}

Soils deliver the regulating ecosystem services of water infiltration and distribution, which can be controlled by macropores. Parameterizing macropore hydraulic properties is challenging due to the lack of direct measurement methods. With tension-disc infiltrometry hydraulic properties near saturation can be measured. Differentiating between hydrologically active and non-active pores, at a given water potential, indirectly assesses macropore continuity. Water flow through macropores is controlled by macropore size distribution, tortuosity, and connectivity, which can be directly derived by X-ray computed tomography (CT). Our objective was to parameterize macropore hydraulic properties based on the imaged macropore network of three horizons of an Andosol and a Gleysol. Hydraulic conductivity $K_{\text {unsat }}$ was derived from infiltration measurements. Soil cores from the infiltration areas were scanned with X-ray CT. $K_{\text {unsat }}$ was significantly higher in the Andosol than in the Gleysol at all water potentials, and decreased significantly with depth in both soils. The in situ measurements guided the definition of new macroporosity parameters from the X-ray CT reconstructions. For the Andosol, $K_{\text {unsat }}$ was best predicted using the imaged-limited macroporosity. A low total macroporosity, coupled with a high macropore density, indicated the abundance of smaller macropores, leading to homogeneous matrix flux. Imaged macropores were not well connected. In contrast, the Gleysol had a bi-modal macropore system with few very-large, but well-connected macropores. $K_{\text {unsat }}$ was best predicted using the imaged macroporosity consisting only of macropores with diameters between 0.75 and 3 $\mathrm{mm}$. Our research demonstrates that linking traditional soil physical measurements with soilvisualization techniques has a huge potential to improve parameterizing macropore hydraulic properties. The relevance of the relationships found in this study for larger scales and other 
soil types still needs to be tested, for example by a multi-scale investigation including a much wider range of different soils.

Keywords: Soil structure; Pore network; Image analysis; Hydraulic parameters; Tension disc infiltrometry. 


\section{Introduction}

Macropores are pores with a diameter larger than $0.3 \mathrm{~mm}$ (Jarvis, 2007) which are arranged in a complex and connected network intermixed with unconnected matrix elements. They are made of earthworm channels, fissures, channels from decaying roots, and inter-aggregate voids. The importance of macropores as preferential pathways of water, air, and chemicals in the soil has long been recognized (Clothier et al., 2008; Jarvis et al., 2007). Some 30 years ago, Watson and Luxmore (1986) reported that water flux through macropores can be as high as $70 \%$ of the total flux and thus are the governing process, even though macropores form only a small fraction of the total soil volume. Despite intensive research over many decades, macropores still constitute a major challenge for modelling flow and transport processes due to their high spatio-temporal variability (Jury et al., 2011). In addition, there is a lack of methods to parameterise hydraulic properties of macropores in order to account adequately for their contribution to fluxes.

Recent advances in 3-D X-ray computed tomography (CT) and image analysis technologies, as well as the increasing availability of $\mathrm{X}$-ray $\mathrm{CT}$, have rekindled the interest in modelling preferential flow processes at the pore scale (Jarvis et al., 2016). The X-ray CT has been applied to characterize inter alia, pore networks, biomass distribution, root architectures, bulk density, organic matter distribution and transport parameters (Hamamoto et al., 2016; Naveed et al., 2013; Nunan et al., 2006; Pierret et al., 2002; Tracy et al., 2010; Wang et al., 2012). In fact, a number of reviews have been published on the successful application and the potential of applying X-ray CT in soil science (Cnudde et al., 2006; Helliwell et al., 2013; Schlüter et al., 2014; Wildenschild et al., 2002). One reason for applying X-ray CT in soil science is to link the geometrical features analyzed, applying X-ray CT to soil functions such as water flow, gas exchange, and solute transport (Deurer et al., 2009; Katuwal et al., 2015; Larsbo et 
al., 2014; Paradelo et al., 2016; Rabbi et al., 2016). The outcome of such a linkage could be that the prediction of properties and processes that cannot be easily measured and observed might be improved and facilitated with structural parameters (Vogel et al., 2010). Vogel et al. (2010) concluded that there are basically two alternative approaches. The first method is to use the structural parameters derived from X-ray CT and use them directly as realistic boundary conditions for the simulation of soil functions (Naveed et al., 2016; Vogel et al., 2005). A problem with this approach is the large computational power required which dictates the scale of the simulations. Scheibe et al. (2015) discussed the problem associated with pore-scale modelling at a smaller scale than the representative elementary volume (REV) of the macroscopic behaviour of the processes. They successfully demonstrated pore-scale modelling at the decimetre scale integrating structural parameters measured with X-ray CT. The aim of the second approach is to establish a quantitative, statistically based relationship between measured structural parameters and hydraulic properties (Samouëlian et al., 2007). The direct quantification, reconstruction, and visualization of 3-D macropore networks allow correlating macropore characteristics to the water and solute transport, as well as gas exchanges in soils. Here we have applied this indirect approach to link structural parameters to the hydraulic parameters of macropores derived with tension-disc infiltrometry. Tension-disc infiltrometry enables measuring near-saturated hydraulic properties in situ (Reynolds and Elrick, 2005). Soil macropores are only hydraulically active in this water pressure head range close to saturation (Ankeny et al., 1990). Macroporosity, the number of macropores, pore length, their pore size distribution, and also their 3-D geometry and topology including continuity, tortuosity, and connectivity are important characteristics impacting on water and solute flow through macropores (Bastardie et al., 2005; Luo et al., 2010a). However, these 3-D characteristics are difficult to quantify with traditional 
methodologies such as the analysis of thin sections (Prado et al., 2007). While tension-disc infiltrometry allows to differentiate between hydrologically active and non-active pores at a given tension, but the continuity of macropores can only indirectly derived from these measurements.

To link soil structure and function, relevant soil macropore features need to be identified and quantified. Our objective was to investigate the role of macropore topological features on the hydraulic properties derived with in situ infiltration measurements of soils with different parent materials and textures.

\section{Material and methods}

\subsection{Soils studied}

The sites represent two soil orders with contrasting soil texture and structure that were known for differing filtering behavior for bacteria and viruses (Aislabie et al., 2001; McLeod et al., 2001). The first soil was classified as a Typic Orthic Allophanic Soil ((Hewitt, 1998); Andosol (IUSS Working Group WRB, 2006); Typic Hapludand (US)) and the second soil was classified as a Typic Orthic Gley Soil ((Hewitt, 1998); Gleysol (IUSS Working Group WRB, 2006); Typic Endoaquept (US)). Both sites were under permanent pasture and grazed by cattle and are located in Waikato, North Island, New Zealand.

\subsection{Tension-disc infiltration measurements}

In March 2011, we measured infiltration rates at four different tension heads $(h=-10,-20$, 40, $-70 \mathrm{~mm}$ ) over three depths of both soils. The depths were chosen to represent three distinct soil genetic horizons: the topsoil (Ah), the upper (Bw1 or Bg1), and lower subsoil (Bw2 or Bg2) layers of the two soils (Table 1). All measurements were conducted in triplicate with 
a tension-disc infiltrometer with a $100-\mathrm{mm}$ radius base. To ensure good contact between the disc and the topsoil, the grass was cut to the ground, and a thin layer of acid-washed sand was evenly spread across the soil surface. Flow measurements were stopped when steadystate flow was reached, as defined in Deurer et al. (2008). The theoretical basis for using tension infiltrometry to derive hydraulic properties has been detailed elsewhere (e.g., Ankeny et al., 1991; Perroux and White, 1988; Reynolds and Elrick, 1991; Reynolds and Elrick, 2005; Vandervaere et al., 2000). We derived the unsaturated hydraulic conductivity at several tensions, following Reynolds and Elrick (2005) who adapted the theory of infiltration from a shallow circular pond (Wooding, 1968).

Applying the capillary-rise equation allows calculating the maximum water filled pore size $r$ (m) at a specific height $h(\mathrm{~m})$ :

$r=2 \sigma \cos (\alpha) / \rho g h$

where $\sigma$ is the surface tension of water $\left(\mathrm{N} \mathrm{m}^{-1}\right), \alpha$ the contact angle between water and the pore wall, which is assumed to be zero, $\rho$ the specific density of water $\left(\mathrm{kg} \mathrm{m}^{-3}\right)$, and $g$ the acceleration due to gravity $\left(\mathrm{g} \mathrm{m}^{-2}\right)$. According to the capillary rise equation, infiltration at tension heads of $-10 \mathrm{~mm},-20 \mathrm{~mm},-40 \mathrm{~mm}$ and $-70 \mathrm{~mm}$ will exclude pores from flow processes, which have equivalent pore radii greater than $1.48,0.74,0.37$ and $0.21 \mathrm{~mm}$, respectively.

\subsection{Basic soil properties}

Intact soil-cores for determining bulk density and bulk soil for measuring texture and organic carbon contents were collected close to all measurement points. The bulk soil was air dried, sieved to $2 \mathrm{~mm}$ prior to further analysis. The texture was determined by a combined sieve and hydrometer method (Gee and Or, 2002). Total soil organic carbon (SOC) was analysed by 
the Dumas method for \%C using a 'Leco TruMac' instrument (Blakemore et al., 1987). Bulk density was determined following standard procedures on intact soil cores of $100 \mathrm{~cm}^{3}$, which were also used for measuring the total porosity and macroporosity at $h=-10 \mathrm{~mm}$ (Blakemore et al., 1987).

\subsection{X-ray computed tomography}

We extracted undisturbed soil cores (40 mm diameter and $50 \mathrm{~mm}$ length) with PVC-sleeves from the centre of each of the infiltration areas immediately after completion of the experiments to relate the macropore architecture - as determined by X-ray CT analysis - to the results of the tension infiltrometry. The soil cores were stored at $4^{\circ} \mathrm{C}$ until analysis. The scanning of the soil cores in the PVC sleeves was performed with the $160 \mathrm{kV} \mathrm{X-ray} \mathrm{source} \mathrm{at}$ $150 \mu \mathrm{A}$. In each scan 1250 angular projections images were collected and each radiograph was averaged over 32 frames. Ring artefacts were minimized during data acquisition and a $0.5 \mathrm{~mm}$ copper filter was used to reduce beam hardening. The software package CT-Pro v.1.0 (Metris X-tek Systems Ltd., Hertfordshire, United Kingdom), which employs the filtered backprojection algorithm for $\mathrm{CT}$ reconstruction, was used to obtain the three-dimensional maps of attenuation coefficients from the two-dimensional angular projections. The threedimensional images of attenuation coefficients with the isotropic voxel size of $0.0734 \mathrm{~mm}$ were then translated into a continuous stack of two-dimensional 16-bit TIFF images using the software VGStudio MAX 1.2.1 (Volume Graphics GmbH, Heidelberg, Germany). Each image slice of the stack had the thickness of $73.4 \mu \mathrm{m}$ and an in-plane resolution of $0.0734 \times 0.0734$ $\mathrm{mm}$.

The images were analysed using ImageJ v1.51p software (Schneider et al., 2012). The images were pre-processed to adjust the brightness and contrast using enhance contrast command 
in ImageJ and cropped to remove the cylinder wall. Segmentation of the images was achieved by combining two different methods. First a local threshold method of Sauvola and Pietikäinen (2000) was applied. The local segmentation algorithm calculates a threshold value for each pixel $T(x, y)$ based on the mean $m(x, y)$ and standard deviation $s(x, y)$ of the intensity values of pixels within a specified neighbourhood $w$ about the pixel as:

$T(x, y)=m(x, y)\left[1+k\left(\frac{s(x, y)}{R}-1\right)\right]$

where $R$ is the dynamic range of standard deviation and $k$ is a constant with values between 0.2 and 0.5 (Phansalkar et al., 2011). The best segmentation results were obtained with $w=$ $5, R=200$ and by adjusting the value of the parameter $k$ between $0.2-0.3$ for the different soils. The algorithm generally worked well for segmenting the air-filled pore spaces. However, for large pores the boundaries of the pores were well delineated but pixels close to the centre of the pores were not correctly segmented. To eliminate this problem, the pre-processed gray-scale images were segmented again using an image histogram based algorithm. The minimum method in ImageJ was applied, which iteratively smoothes the image histogram until two clear peaks are obtained and then chooses the local minima between these two peaks as the threshold. The segmentation results obtained from the two methods were combined to obtain the final segmentation results. As a post-processing step, features with diameter less than twice the image resolution (i.e. $0.147 \mathrm{~mm}$ ) were removed from the segmented images, thus the analysed pore properties refer to pores greater than or equal to $0.147 \mathrm{~mm}$ in diameter These are also referred to as macropores in the study, unless otherwise stated.

Using the post-processed segmented images the macroporosity density, the number of macropores in a unit soil volume $\left(M P D\right.$, number $\left.\mathrm{mm}^{-3}\right)$, total macroporosity $\left(T M P, \mathrm{~mm}^{3} \mathrm{~mm}^{-}\right.$ 
${ }^{3}$ ), volume of macropores connected from the top to the bottom per unit soil volume (CTMP, $\mathrm{mm}^{3} \mathrm{~mm}^{-3}$ ), and the macroporosity distribution along the soil depth were determined. The minimum value of macroporosity along the soil depth at depth interval corresponding to one voxel depth was determined and referred to as limiting total macroporosity. The connectivity of the macropores and their average diameter were determined using Particle Analyser plugin within the BoneJ plugin (Doube et al., 2010) in ImageJ. The connectivity of macropores in a soil core was calculated by obtaining the Euler characterisitcs of the pore networks using BoneJ plugin and quantified as the Genus density, i.e. the total number of redundant connections per unit soil volume (Vogel et al., 2010). The mean diameter of macropores (MPDIA) in $\mathrm{mm}$ in a soil core was calculated as the volume weighted average of the average macropore thickness of each macropore within a soil column as:

$M P D I A=\sum_{i=1}^{n} V_{i} d_{i} / \sum_{i=1}^{n} V_{i}$

where $n$ is the number of macropores, $V^{i}$ is the volume of $i^{\text {th }}$ macropore $\left(\mathrm{mm}^{3}\right)$, and $d_{i}$ its average thickness/diameter $(\mathrm{mm})$ determined using the algorithm by Dougherty and Kunzelmann (2007) and implemented within the BoneJ plugin in ImageJ. This algorthim is based on determining the diameter of the largest sphere which completely fits within the pore structure at each point along its centreline. The average thickness of a single pore structure within a soil column is then calculated as the volume weighted average of the largest spheres at each point along the centreline of the pore structure. The vertical tortuosity of the macropores was determined as an average value of the ratio of the actual length of a macropore to the vertical distance between the ends of the macropore. This was achieved by obtaining the skeletons of the macropores, namely the centreline of the macropores using Skeletonize 3D and Analyze Skeletons plugin within BoneJ. The effect of uneven surface of the 
macropore wall on the quantification of vertical tortuosity was eliminated by removing features less or equal to $0.147 \mathrm{~mm}$ from the skeletons of the macropores.

Linking the infiltration experiments with the flow-active pores was further facilitated by dividing the macropores into different size classes corresponding to the water potentials used in the infiltration experiments. The plugin 'Shape Filter' (Wagner and Lipinski, 2013) in ImageJ was used for filtering macropores based on the diameter (minimum Feret's diameter) into different size classes ( $<0.43 \mathrm{~mm}, 0.43-3 \mathrm{~mm}, 0.75-3 \mathrm{~mm}$ and $1.5-3 \mathrm{~mm}$ ).

\subsection{Statistical analysis}

A general analysis of variance with two fixed effects (soil type, horizon) was used to determine if the mean values of the macropore properties of the soils were significantly different. We interpreted the differences between averages of macroporosity characteristics and hydraulic properties to be significant if they were larger than their respective least significant differences (LSD) at the 95\% confidence level $(P \leq 0.05)$. Pairwise Multiple Comparison Procedures (Holm-Sidak method) was used as a post hoc test. Parameters that did not follow the normal distribution were log transformed prior to the analysis. Additionally, Pearson correlation and linear regression analyses were performed. All statistical tests were conducted at the $95 \%$ confidence level using the software Sigma Plot 12.05 (Systat Software Inc.).

\section{Results and discussion}

\subsection{General description of soils}

Selected soil properties for the two soils are provided in Table 1. The Andosol had greater silt and sand contents than the Gleysol, which was characterized as a clay loam. The Andosol's 
texture was described as a gritty silt loam. The topsoil structure of the Gleysol was strongly developed and medium or coarse polyhedral. The subsoil structure was coarse prismatic with a low porosity within the prism structure. The prismatic structures in the subsoil showed large cracks which were often coated with translocated organic matter, silt, or clay (McLeod et al., 2008). In contrast, the Andosol had a weakly developed fine polyhedral structure with single grains and a high porosity. Both soils had clay contents above $20 \%$ and a clay to organic carbon ratio larger than 3 in all horizons (Table 1), and, hence, were expected to exhibit a potential for preferential flow (Koestel and Jorda, 2014). Bulk density of the Andosol did not change with depth, while the bulk desnity of the Gleysol increased with depth in line with increasing clay contents and decrasing organic carbon contents (Table 1).

\subsection{Visualization and quantification of macropore networks}

Macropore networks were reconstructed using the binary images acquired with X-ray CT. The six macropore networks shown in Figure 1 are representative of the three horizons of both soils. In total 18 soil cores were scanned. The red colour represents macropores larger than $0.147 \mathrm{~mm}$, the resolution of the X-ray CT images. The macroporosity was based on pores with a diameter larger than $0.147 \mathrm{~mm}$ and is referred to as total macroporosity $\left(T M P_{(>0.147)}\right)$.

It has to be noted that the macropore networks in our soils developed under permanent grassland and thus have not been disturbed through cultivation for at least a decade. The macropore networks were distinctly different for the two soils. The average macropore diameter was $0.244 \pm 0.008 \mathrm{~mm}$ in the Andosol as compared to $0.315 \pm 0.015 \mathrm{~mm}$ in the Gleysol (Table 2). In particular, in the lower subsoil of the Andosol (Figure 1, bottom), the macropores were of small diameter and tubular. Relatively narrow and round macropores are typical for macropores formed by roots, which decrease in size with depth (Luo et al., 2010b). 
In the Gleysol, the macropores were shaped differently, as they were more tortuous and more randomly organized. They might have been formed in wetting and drying cycles through the swelling and shrinkage of the abundant clay minerals in the Gleysol. Significant $(P \leq 0.05)$ differences were observed between the average tortuosity values among both horizons and soils. Maximum and minimum tortuisity was 2.585 and 2.84 for the Andosol and 2.986 and 3.5 for the Gleysol, respectively. The average tortuosity for each horizon and soil type (Table 2) was much higher than those reported in the literature for arable soils (Katuwal et al., 2015) and grassland soils (Peth et al., 2008) reflecting the high biological activity of the two permanent grassland soils included in our study, which have not been disturbed through cultivation for at least a decade.

The macropore density was significantly $(P \leq 0.001)$ higher in the Andosol than in the Gleysol. Moreover, it tended to increase $(P=0.05)$ with depth (Table 2$)$. The differences between the average macropore diameters of the two soils were significant $(P \leq 0.001)$. The average mean macropore diameter of the two soils decreased significantly $(P \leq 0.001)$ with depth (Table 2$)$. The average mean macropore diameter of the Ah-, Bg1-, and Bg2-horizons was $0.378( \pm 0.013)$ $\mathrm{mm}, 0.278( \pm 0.005) \mathrm{mm}$, and $0.288( \pm 0.002) \mathrm{mm}$, respectively. The average mean macropore diameter of the three horizons Ah, Bw1, and Bw2 of the Andosol were $0.272( \pm 0.004) \mathrm{mm}$, $0.237( \pm 0.002) \mathrm{mm}$, and $0.222( \pm 0.004) \mathrm{mm}$, respectively (Table 2$)$.

The total macroporosity determined for the three horizons of the two soils ranged between 0.192 and $0.029 \mathrm{~mm}^{3} \mathrm{~mm}^{-3}$, with an average of $0.06 \mathrm{~mm}^{3} \mathrm{~mm}^{-3}$ (Table 2). These are in the range of those reported for soils under permanent pasture in the literature. For example, in the top $0.1 \mathrm{~m}$ of silt loam soils under apple orchards in New Zealand, Deurer et al. (2009) found an average macroporosity of 0.025 and $0.075 \mathrm{~mm}^{3} \mathrm{~mm}^{-3}$ under integrated and organic orchard management, respectively. Luo et al. (2010b) analysed CT-images of cores taken from 
the top $0.35 \mathrm{~m}$ of a fine-textured silt loam soil and a fine-loamy soil and reported average macroporosities of 0.061 and $0.031 \mathrm{~mm}^{3} \mathrm{~mm}^{-3}$, respectively. They defined macropores as pores with a diameter greater than $0.75 \mathrm{~mm}$. Perret et al. (1999) determined macroporosities between 0.022 and $0.038 \mathrm{~mm}^{3} \mathrm{~mm}^{-3}$ for $800 \mathrm{~mm}$ long undisturbed soil cores extracted from a sandy loam soil under grassed field borders. In our study, the total macroporosity of the Gleysol was $0.141 \pm 0.027 \mathrm{~mm}^{3} \mathrm{~mm}^{-3}$ and was significantly $(P \leq 0.001)$ larger than in the Andosol, which had an average total macroporosity of $0.065 \pm 0.004 \mathrm{~mm}^{3} \mathrm{~mm}^{-3}$; it varied greatly with depth, and decreased significantly $(P \leq 0.001)$ from the topsoil to the two subsoil horizons. In both soils, the macroporosities of the two subsoil horizons were comparable. Decreasing macroporosities with depth have been observed in previous studies (Katuwal et al., 2015; Naveed et al., 2013).

The connected total macroporosity $(\operatorname{CTMP}(>0.147))$, which only considers macropores that are connected from the top to the bottom of a core ranged from 0.185 to $0.005 \mathrm{~mm}^{3} \mathrm{~mm}^{-3}$ with an average of $0.049 \mathrm{~mm}^{3} \mathrm{~mm}^{-3}$. The total connected macroporosity of the Andosol $(0.022 \pm$ $\left.0.007 \mathrm{~mm}^{3} \mathrm{~mm}^{-3}\right)$ was significantly $(P \leq 0.001)$ smaller than in the Gleysol $\left(0.075 \pm 0.017 \mathrm{~mm}^{3}\right.$ $\left.\mathrm{mm}^{-3}\right)$. Similar to the $T M P_{(>0.147)}$ it decreased significantly $(P \leq 0.001)$ from the topsoil to the subsoil. In the Andosol, the $C T M P_{(>0.147)}$ contributed 74,31 and $20 \%$ to the $T M P(>0.147)$ in the topsoil, upper, and lower subsoil, respectively, while in the three horizons of the Gleysol it exceeded $75 \%$ for all horizons ranging between 79 and $94 \%$ (Table 2). The largest number of connected macropores was five in the upper subsoil of the Andosol for all horizons. Generally only 1 or 2 macropores were found that connected the top to the bottom of a core. This indicates a strong connectivity of the macropores in both the horizontal and vertical directions. In addition, genus density was also calculated to account for the connectivity of the pores. It ranged from 0.309 to $2.276 \mathrm{~mm}^{-3}$ for the Gleysol and from 0.144 to $1.057 \mathrm{~mm}^{-3}$ 
for the Andosol, respectively, and the differences between soils and horizons were significant $(P \leq 0.05)$. The higher connectivity of the macropores in the Gleysoil than in the Andosol corroborates the findings of Luo et al. (2010) and Katuwal et al. (2015), who reported more connectied cmacopore networks in soils with larger macroporosities.

\subsection{Tension-disc infiltrometry}

Results of the tension-disc infiltrometry are presented in Figure 2. The highest unsaturated hydraulic conductivity was measured in the Andosol at the water potential nearest to saturation $K_{\text {unsat }}(-10 \mathrm{~mm})$ at $8.15 \pm 3.86 \mathrm{~mm} \mathrm{~h}^{-1}$. The comparable average unsaturated hydraulic conductivity in the Gleysol was $6.6 \pm 2.68 \mathrm{~mm} \mathrm{~h}^{-1}$, while the average unsaturated hydraulic conductivities were generally higher in the Andosol than in the Gleysol for all three horizons (Figure 2). The difference between the two soils was not significant $(P>0.05)$ for the water potential $h=-10 \mathrm{~mm}\left(K_{\text {unsat }}(-10 \mathrm{~mm})\right)$. Unsaturated hydraulic conductivities displayed a high spatial variability with coefficients of variation ranging between 1 and $113 \%$ for the Andosol and between 12 and 93\% for the Gleysol, respectively. For the topsoil and upper subsoil of the Andosol, the highest variability was observed close to saturation, probably associated with high biological activities and the resulting biopores. Generally, the highest variability, however, was observed in the lower subsoil possibly. Shoji et al. (1993) reported greater unsaturated hydraulic conductivities in Andosols than other mineral soils in the water potential range of 0 to $-100 \mathrm{~mm}$. They attributed this to the higher 'ratio of the cross-sectional area for unsaturated flow to the total soil cross sectional area'.

In the water potential range from -70 to $-10 \mathrm{~mm}$, the unsaturated hydraulic conductivity increased by one order of magnitude in the topsoil of the Andosol and by two orders of magnitude in the topsoil of the Gleysol, respectively. A larger increase was expected for the 
finer textured and structured clay in comparison with the coarser, single-grain, poorly structured silt loam (Jarvis and Messing, 1995). In the structured Gleysol, surface-vented macropores were of greater importance for unsaturated flow than in the Andosol. The hydraulic conductivities at different water potentials suggest at least a bimodal pore system for the topsoil of the Gleysol with one or two break-points dividing the pore systems between -20 and $-40 \mathrm{~mm}$. In contrast, a linear regression fitted the hydraulic conductivity - tension pairs $\left(R^{2}=0.98\right)$ of the Andosol's topsoil - indicating a homogeneous pore distribution (Figure 2). In the subsoils, in particular in the lower subsoil of the Andosol, the unsaturated hydraulic conductivity was low and varied little with water potential (Figure 2).

The near-saturated hydraulic conductivity decreased with depth in both soils at the water potentials $K_{\text {unsat }}(-10 \mathrm{~mm})$ and $K_{\text {unsat }}(-20 \mathrm{~mm})$ (Figure 2$)$. The hydraulic conductivities were significantly $(P<0.05)$ higher in the topsoil and the upper subsoil than in the lower subsoil at these two water potentials which is related to the higher clay content of the subsoil and the higher consolidation of the subsoil compared with the topsoil. At the water potentials $K_{\text {unsat }}(-$ $70 \mathrm{~mm}$ ) and $K_{\text {unsat }}(-40 \mathrm{~mm})$, the unsaturated hydraulic conductivity of the upper subsoil was significantly $(P<0.05)$ higher than those in the topsoil and the lower subsoil. Generally, greater hydraulic conductivities can be attributed to better pore continuity.

\subsection{Correlation analysis of macropore network characteristics}

Significant strong correlations were found between most of the macropore characteristics assessed by CT-images (Table 3). The joint correlation analyses for the two soils required that the parameters macroporosity, mean macropore diameter, genus density and the hydraulic onductivities needed to be log transformed to fullfill the requirement of normal distributed data. The analysis showed that $\log$ (macroporosity), log(mean macropore diameter), and 
connectivity (genus density) were positively correlated (Table 3), indicating that larger macroporosities were associated with a more-connected macropore network with on average larger macropores. Vertical tortuosity was the only structural parameter derived from X-ray CT that was not correlated with the other structural parameters analysed, with the exception of the macropore density.

The log-values of the unsaturated hydraulic conductivity determined at a water potential of $70 \mathrm{~mm}$ were highly correlated with all structural parameters, except the log values of connectivity. Soils with higher flow rates had a larger proportion of smaller pores $(<0.75 \mathrm{~mm})$ than soils with low flow rates. In comparison, the log-values of the unsaturated hydraulic conductivity determined at a water potential of $-10 \mathrm{~mm}$ diameter were only significantly $(P$ $<0.05)$ correlated to tortuosity and the log values of connectivity, but not to the log values of total macroporosity (Table 3). In contrast, Larsbo et al. (2014) reported significant correlations between the X-ray CT macroporosity and $K_{\text {unsat }}(-10 \mathrm{~mm})$, measured with tension-disc infiltrometer, but not with $K_{\text {unsat }}(-50 \mathrm{~mm})$. They explained their findings by noting that the pores conducting at a water potential of $-50 \mathrm{~mm}$ would have been mostly smaller than the resolution of their images $(0.485 \mathrm{~mm})$. The resolution of our images with $0.0734 \mathrm{~mm}$ was about 3-times higher than the maximum macropore diameter of pores active $(0.430 \mathrm{~mm})$ at a water potential of $-10 \mathrm{~mm}$. This resolution cannot explain the lack of correlation between total macroporosity and near-saturated hydraulic conductivities. Others have found significant positive correlations between saturated hydraulic conductivities and macroporosities (e.g., Luo et al., 2010b). The macroporosity determined at $h=-10 \mathrm{kPa}$ (Table 1) was not correlated to the total macroporosity assessed by X-ray CT $(P=0.347)$, indicating that different pore sizes dominated the different measures of macroporosities. This can be 
explained by the fact that smaller macropores that are not captured by X-ray CT are integrated in this measure.

3.5. Relationship between X-ray computed tomography macroporosity and unsaturated conductivity

Figure 3 shows the relationships between unsaturated conductivity, derived from in situ tension-disc infiltrometer measurements, and different measures of macroporosity, derived from the X-ray CT images separately for the Andosol and the Gleysol. The macroporosities derived include the total macroporosity $\left(T M P_{(>0.147)}\right)$ and connected total macroporosity $\left(C T M P_{(>0.147)}\right)$. In a linear regression, 76 and $62 \%$ of the variability in the unsaturated hydraulic conductivity measured in situ at a tension of $-10 \mathrm{~mm}$ were explained in all horizons of the Gleysol and the Andosol with the total macroporosity $\left(T M P_{(>0.147)}\right)$, respectively (Figure 3a and b). The results were similar when $K_{\text {unsat }}(-10 \mathrm{~mm})$ was regressed with the connected total macroporosity $(C T M P(>0.147))$ (Figures $3 c$ and $d)$. The results of the in situ infiltration measurements suggest a bimodal pore system for the Gleysol, with a break-point dividing the pore systems in all horizons somewhere around a pore diameter of $0.74 \mathrm{~mm}$, equivalent to a water potential of $-40 \mathrm{~mm}$. At and below this water potential, infiltration rates dropped to insignificant rates (Figure 2). Considering this information from the field measurements, a new macroporosity, the macroporosity consisting only of macropores with diameters between 0.75 and $3 \mathrm{~mm}\left(M P_{(3-0.75)}\right)$ was extracted from the $\mathrm{X}$-ray $\mathrm{CT}$ images. The new structural parameter $M P_{(3-0.75)}$ limits the total macroporosity to the pores, theoretically conducting flow in the respective water potential range -10 to $-40 \mathrm{~mm}$, and isolates the macropores that conducted the majority of the flux in the tension-disc infiltrometer measurements. About $78 \%$ of the variability in the unsaturated hydraulic conductivity for the 
tension range between - 40 and $-10 \mathrm{~mm}$ was explained in all horizons of the Gleysol with $M P_{(3-}$ 0.75) (Figure 3e). In the next step, the macroporosity was further reduced by excluding all macropores that were not connected from the top to the bottom of the cores. So, only the active macropores are included in the new macroporosity parameter $\operatorname{CTMP}_{(3-0.75)}$. The relationship between macroporosity and the unsaturated conductivity for the Gleysol was further improved. The resulting regression coefficient increased to $86 \%$ (Figure $3 \mathrm{~g}$ ). As expected from the results of the infiltration measurements with the Andosol, regressing the measured unsaturated conductivities with the same macroporosity parameters for the Andosol did not improve the results. In fact, the goodness of the fit of the linear regression decreased (Figures $3 f$ and $h$ ), supporting the findings of the infiltration measurements, which predicted a homogeneous pore system for the Andosol (Figure 2).

The depth distributions of the total macroporosity $(T M P(>0.147))$, and the connected total macroporosity $(C T M P(>0.147))$, are shown in Figures $4 a$ and $4 c$ for the Gleysol, and in Figures $4 \mathrm{~b}$ and $4 \mathrm{~d}$ for the Andosol, respectively. The general patterns observed in the two soils were similar. Total macroporosity exhibited a high variability in the topsoils, but in both soils there was typically an increase of the total macroporosity from the soil surface to about 20 or 25 $\mathrm{mm}$ depth, followed by a gradual decrease of the total macroporosity. The low total macroporosity at the soil surface for the two soils was likely associated with compaction caused by grazing. The higher total macroporosity at $25 \mathrm{~mm}$ depth might be explained by earthworm activities and ramification by roots. In the upper subsoil of the two soils (Bw1 and Bg1), total macroporosity was generally less variable, and about half of the average total macroporosity determined in the topsoils. The total macroporosity further decreased with depth, and reached its minimum in the lower subsoil for both soils. The lower subsoil of the Andosol had the lowest average total macroporosity of all horizons. Over the $30 \mathrm{~mm}$ of each 
of the two subsoil layers analyzed, $T M P_{(>0.147)}$ remained more or less constant. A decline in macroporosity with depth has been observed by others (Ersahin et al., 2002) and been attributed to changes in structure and bulk density. The decrease in organic carbon contents in the subsoils would have further contributed to lower macroporosities at depth in our study. The connected total macroporosity of the Gleysol followed the trend of $T M P_{(>0.147) \text {, but for }}$ the Andosol the $C T M P_{(>0.147)}$ was much lower in the two subsoils than the $T M P_{(>0.147) .}$

The macroporosity of a soil is composed of clusters of highly connected pores of different diameters and isolated features. Not the entire macroporosity is conductive due to dead-end macropores, bottleneck situations, and restrictions in the pore diameters. Flow might be restricted for parts of the macroporosity because of changing pore widths, but also air inclusions might cut off parts of the macropore network from flux (Jarvis, 2007). This has been shown in previous studies applying X-ray CT while conducting solute transport experiments (Sammartino et al., 2015). In our study, the much lower connected total macroporosity of the Andosol clearly indicated that many of the macropores of the Andosol determined by X-ray CT were not conductive because they were not connected from the top to the bottom of a soil core (Figures 4c and d; Table 2). In contrast, most of the measured macroporosity of the Gleysol was connected and thus conductive. Therefore, regressing the limited macroporosity with the unsaturated hydraulic conductivity improved the relationship for the Andosol considerably while the relationship between limited macroporosity and unsaturated hydraulic conductivity was similar to previous relationships for the Gleysol (Figures $4 e$ and f). The regression coefficients were 83 and $69 \%$ for the Gleysol and the Andosol, respectively. Larsbo et al. (2014) found that soil cores with smaller macroporosity determined by X-ray CT had smaller near-saturated conductivities. In contrast, in our study the Andosol, which had the smaller imaged macroporosity, had significantly higher near-saturated conductivities than 
the Gleysol. The macropore network of the andosol was more homogeneous, with a significantly higher macropore density and significantly smaller average mean macropore diameter than those of the Gleysol. This suggests that for the Andosol, pores that are not visible at the resolution of the X-ray CT images, were important for unsaturated hydraulic conductivity.

\section{Conclusions}

Our linking of in situ measurements of unsaturated conductivities guided the definition of new macroporosity parameters from X-ray CT reconstructions of the two contrasting soils. Our measurements discerned different flow mechanisms for the two soils. A comparatively low total macroporosity, coupled with a high macropore density, indicated the abundance of many smaller macropores, which leads to homogeneous matrix flux in the Andosol. The relatively small macroporosity of this soil was not well connected. Thus, the near saturated hydraulic conductivity was best predicted for this soil using the imaged-limited macroporosity. In contrast, the Gleysol had a bi-modal macropore system with a few very large, but well-connected, macropores. This results in preferential flow. In this soil, the nearsaturated hydraulic conductivity was best predicted using the imaged macroporosity consisting only of macropores with diameters between 0.75 and $3 \mathrm{~mm}$, which were the conductive pores confirmed by the in situ measurements.

In a further perspective, the research presented here demonstrates that linking traditional soil physical measurements with rapidly evolving soil visualization techniques at the small scale is a powerful tool towards better parameterization of simulation models. This will lead to an improved understanding and quantification of essential ecosystem services of soils, such as the regulation of water and gas fluxes and contaminant filtering. More soil types need to 
be analysed to draw firmer conclusions on the dependence between structural parameters and near-saturated hydraulic conductivity. It also needs to be confimed that the relationships found in this study are relevant for larger scales. This could be achieved by a multi-scale investigation, which should also include a much wider range of different soils.

\section{Acknowledgement}

This research was funded through Landcare Research and the Ministry for Business, Innovation and Employment (Contract 1314-32-001K). Parts of the work were supported by the European Union's Horizon 2020 Research and Innovation Project under grant agreement No. 645717 (PROTINUS project). We thank Drs Markus Deurer and John Scott for initiating this research. 


\section{References}

Aislabie, J., Smith, J.J., Fraser, R., McLeod, M., 2001. Leaching of bacterial indicators of faecal contamination through four New Zealand soils. Aust. J. Soil Res. 39, 1397-1406.

Ankeny, M.D., Ahmed, M., Kaspar, T.C., Horton, R., 1991. Simple field method for determining unsaturated hydraulic conductivity. Soil Sci. Soc. Am. J. 55, 467-470.

Ankeny, M.D., Kaspar, T.C., Horton, R., 1990. Characerization of tillage and traffic effects on unconfined infiltration measurements. Soil Sci. Soc. Am. J. 54, 837-840.

Bastardie, F., Capowiez, Y., Cluzeau, D., 2005. 3D characterisation of earthworm burrow systems in natural soil cores collected from a 12-year-old pasture. Appl. Soil Ecol. 30(1), 34-46.

Blakemore, L., Searle, P.L., Daly, B.K., 1987. Methods for Chemical Analysis of Soils. New Zealand Soil Bureau Scientific Report 80, pp. 103.

Clothier, B.E., Green, S.R., Deurer, M., 2008. Preferential flow and transport in soil: progress and prognosis. Eur J Soil Sci 59(1), 2-13.

Cnudde, V., Masschaele, B., Dierick, M., Vlassenbroeck, J., Hoorebeke, L.V., Jacobs, P., 2006. Recent progress in X-ray CT as a geosciences tool. Applied Geochemistry 21(5), 826832.

Deurer, M., Clothier, B.E., Green, S., Gee, G., 2008. Infiltration rate, hydraulic conductivity, preferential flow. In: S. Logsdon, D. Clay, D. Moore, T. Tsegaye (Eds.), Soil Science: Step-by-steo field analysis. Soil Science Society of America, Madison, WI, US.

Deurer, M., Grinev, D., Young, I., Clothier, B.E., Müller, K., 2009. The impact of soil carbon management on soil macropore structure: a comparison of two apple orchard systems in New Zealand. European Journal of Soil Science 60, 945-955. 
Doube, M., Kłosowski, M.M., Arganda-Carreras, I., Cordelières, F.P., Dougherty, R.P., Jackson, J.S., 2010. BoneJ: Free and extensible bone image analysis in ImageJ. Bone (47), 10761079.

Dougherty, R., Kunzelmann, K.-H., 2007. Computing Local Thickness of 3D Structures with ImageJ. Microscopy and Microanalysis 13, 1678-1679.

Ersahin, S., Papendick, R.I., Smith, J.L., Keller, C.K., Manoranjan, V.S., 2002. Macropore transport of bromide as influenced by soil structure differences. Geoderma 108, 207223.

Gee, G.W., Or, D., 2002. Particle size analysis. In: J.H. Dame, G.C. Topp (Eds.), Methods of Soil Analysis - Part 4 - Physical Methods. Soil Science Society of America, Madison, Wisconsin, pp. 255-293.

Hamamoto, S., Moldrup, P., Kawamoto, K., Sakaki, T., Nishimura, T., Komatsu, T., 2016. Pore network structure linked by X-ray $\mathrm{CT}$ to particle characteristics and transport parameters. Soils and Foundations 56, 676-690.

Helliwell, J.R., Sturrock, C.J., Grayling, K.M., Tracy, S.R., Flavel, R.J., Young, I.M., Whalley, W.R., Mooney, S.J., 2013. Applications of X-ray computed tomography for examining biophysical interactions and structural development in soil systems: a review. Eur J Soil Sci 64(3), 279-297.

Hewitt, A.E., 1998. New Zealand Soil Classification. Landcare Research Science Series, 1. 2 ed. Manaaki Whenua Press, Lincoln, New Zealand.

IUSS Working Group WRB, 2006. World Reference Base for Soil Resources 2006. A framework for international classification, correlation and communication. 2nd edition. World Soil Resources Reports 103 FAO, Rome. 
Jarvis, N., Koestel, J., Larsbo, M., 2016. Understanding Preferential Flow in the Vadose Zone: Recent Advances and Future Prospects. Vadose Zone J 15(12).

Jarvis, N., Larsbo, M., Roulier, S., Lindahl, A., Persson, L., 2007. The role of soil properties in regulating non-eqilibrium macropore flow and solute transport in agricultural topsoils. European Journal of Soil Science 58, 282-292.

Jarvis, N.J., 2007. A review of non-equilibrium water flow and solute transport in soil macropores: principles, controlling factors and consequences for water quality. Eur J Soil Sci 58(3), 523-546.

Jarvis, N.J., Messing, I., 1995. Near-saturated hydraulic conductivity in soils of contrasting texture measured by tension infiltrometers. Soil Sci. Soc. Am. J. 59, 27-34.

Jury, W.A., Or, D., Pachepsky, Y., Vereecken, H., Hopmans, J.W., Ahuja, L.R., Clothier, B.E., Bristow, K.L., Kluitenberg, G.J., Moldrup, P., Simunek, J., van Genuchten, M.T., Horton, R., 2011. Kirkham's legacy and contemporary challenges in soil physics research. Soil Sci. Soc. Am. J. 75(5), 1589-1601.

Katuwal, S., Moldrup, P., Lamandé, M., Tuller, M., de Jonge, L.W., 2015. Effects of CT Number Derived Matrix Density on Preferential Flow and Transport in a Macroporous Agricultural Soil. Vadose Zone J http://dx.doi.org/10.2136/vzj2015.01.0002.

Koestel, J., Jorda, H., 2014. What determines the strength of preferential transport in undisturbed soil under steady-state flow? Geoderma 217-218, 144-160.

Larsbo, M., Koestel, J., Jarvis, N., 2014. Relations between macropore network characteristics and the degree of preferential solute transport. Hydrology and Earth System Sciences $18,5255-5269$. 
Luo, L., Lin, H., Schmidt, J., 2010a. Quantitative Relationships between Soil Macropore Characteristics and Preferential Flow and Transport. Soil Sci. Soc. Am. J. 74(6), 19291937.

Luo, L., Lin, H.S., Li, S., 2010b. Quantification of 3-D macropore networks in different soil types and land uses using computed tomography. Journal of Hydrology 393, 53-64.

McLeod, M., Aislabie, J., Ryburn, J., McGill, A., 2008. Regionalizing Potential for Microbial Bypass Flow through New Zealand Soils. J Environ Qual 37(5), 1959-1967.

McLeod, M., Aislabie, J., Smith, J., Fraser, R., Roberts, A., Taylor, M., 2001. Viral and chemical tracer movement through contrasting soils. J. Environ. Qual. 30, 2134-2140.

Naveed, M., Moldrup, P., Arthur, E., Wildenschild, D., Eden, M., Lamandé, M., Vogel, H.-J., de Jonge, L.W., 2013. Revealing Soil Structure and Functional Macroporosity along a Clay Gradient Using X-ray Computed Tomography. Soil Sci. Soc. Am. J. 77(2), 403-411.

Naveed, M., Moldrup, P., Schaap, M.G., Tuller, M., Kulkarni, R., Vogel, H.J., Wollesen de Jonge, L., 2016. Prediction of biopore- and matrix-dominated flow from X-ray CT-derived macropore network characteristics. Hydrol. Earth Syst. Sci. 20(10), 4017-4030.

Nunan, N., Ritz, K., Rivers, M., Feeney, D.S., Young, I.M., 2006. Investigating microbial microhabitat structure using X-ray computed tomography. Geoderma 133(3-4), 398-407.

Paradelo, M., Katuwal, S., Moldrup, P., Norgaard, T., Herath, L., de Jonge, L.W., 2016. X-ray CT-Derived Soil Characteristics Explain Varying Air, Water, and Solute Transport Properties across a Loamy Field. Vadose Zone J http://dx.doi.org/10.2136/vzj2015.07.0104(4).

Perret, J., Prasher, S.O., Kantzas, A., Langford, C., 1999. Three-dimensional quantification of macropore networks in undisturbed soil cores. Soil Sci. Soc. Am. J. 63, 1530-1543. 
Perroux, K.M., White, I., 1988. Designs for disc permeameters. Soil Sci. Soc. Am. J. 52, 12051215.

Peth, S., Horn, R., Beckmann, F., Donath, T., Fischer, J., Smucker, A.J.M., 2008. Threedimensional quantification of intra-aggregate pore-space features using synchrotron-radiation-based microtomography. Soil Sci. Soc. Am. J. 72, 897-907.

Phansalkar, N., More, S., Sabale, A., Joshi, M., 2011. Adaptive local thresholding for detection of nuclei in diversity stained cytology images, 2011 International Conference on Communications and Signal Processing, pp. 218-220.

Pierret, A., Capowiez, Y., Belzunces, L., Moran, C.J., 2002. 3D reconstruction and quantification of macropores using X-ray computed tomography and image analysis. Geoderma 106(3-4), 247-271.

Prado, B., Duwig, C., Hidalgo, C., Gómez, D., Yee, H., Prat, C., Esteves, M., Etchevers, J.D., 2007. Characterization, functioning and classification of two volcanic soil profiles under different land uses in Central Mexico. Geoderma 139(3-4), 300-313.

Rabbi, S.M.F., Daniel, H., Lockwood, P.V., Macdonald, C., Pereg, L., Tighe, M., Wilson, B.R., Young, I.M., 2016. Physical soil architectural traits are functionally linked to carbon decomposition and bacterial diversity. Scientific Reports 6, 33012.

Reynolds, W.D., Elrick, D.E., 1991. Determination of hydraulic conductivity using a tension infiltrometer. Soil Sci. Soc. Am. J. 55, 633-639.

Reynolds, W.D., Elrick, D.E., 2005. Measurement and Characterization of Soil Hydraulic Processes. In: J. Álvarez-Benedí, R. Munoz-Carpena (Eds.), Soil-Water-Solute Process Characterization. CRC Press, Boca Raton, pp. 197-252. 
Sammartino, S., Lissy, A.-S., Bogner, C., Van Den Bogaert, R., Capowiez, Y., Ruy, S., Cornu, S., 2015. Identifying the Functional Macropore Network Related to Preferential Flow in Structured Soils. Vadose Zone J http://dx.doi.org/10.2136/vzj2015.05.0070.

Samouëlian, A., Vogel, H.-J., Ippisch, O., 2007. Upscaling hydraulic conductivity based on the topology of the sub-scale structure. Advances in Water Reources 30, 1179-1189.

Sauvola, J., Pietikäinen, M., 2000. Adaptive document image binarization. Pattern Recognition $33,225-236$.

Scheibe, T.D., Perkins, W.A., Richmond, M.C., McKinley, M.I., Romero-Gomez, P.D.J., Oostrom, M., Wietsma, T.W., Serkowski, J.A., Zachara, J.M., 2015. Pore-scale and multiscale numerical simulation of flow and transport in a laboratory-scale column. Wat. Resourc. Res. 51(2), 1023-1035.

Schlüter, S., Sheppard, A., Brown, K., Wildenschild, D., 2014. Image processing of multiphase images obtained via X-ray microtomography: A review. Water Resour Res 50(4), 36153639.

Schneider, C.A., Rasband, W.S., Eliceiri, K.W., 2012. NIH Image to ImageJ: 25 years of image analysis. Nat Meth 9, 671-675.

Shoji, S., Nanzyo, M., Dahlgren, R.A., 1993. Volcanic Ash Soils Genesis, properties and utilization. Elsevier, Amsterdam, Holland.

Tracy, S.R., Roberts, J.A., Black, C.R., McNeill, A., Davidson, R., Mooney, S.J., 2010. The Xfactor: visualizing undisturbed root architecture in soils using X-ray computed tomography. Journal of Experimental Botany 61(2), 311-313.

Vandervaere, J.P., Vaulin, M., Elrick, D.E., 2000. Transient flow from tension infiltrometers: II. Four methods to determine sorptivity and conductivity. Soil Sci. Soc. Am. J. 64, 12721284. 
Vogel, H.-J., Tolke, J., Schulz, V.P., Krafczyk, M., Roth, K., 2005. Comparison of a LatticeBoltzmann model, a Full-Morphology model, and a Pore Network model for determining capillary pressure-saturation relationships. Vadose Zone J 4(2), 380-388.

Vogel, H.J., Weller, U., Schluter, S., 2010. Quantification of soil structure based on Minkowski functions. Computers \& Geosciences 36(10), 1236-1245.

Wagner, T., Lipinski, H.G., 2013. IJBlob: An ImageJ Library for Connected Component Analysis and Shape Analysis. Journal of Open Research Software 1: e6.

Wang, W., Kravchenko, A.N., Smucker, A.J.M., Liang, W., Rivers, M.L., 2012. Intra-aggregate Pore Characteristics: X-ray Computed Microtomography Analysis. Soil Sci. Soc. Am. J. 76(4), 1159-1171.

Watson, K.W., Luxmoore, R.J., 1986. Estimating Macroporosity in a Forest Watershed by use of a Tension Infiltrometer. Soil Sci. Soc. Am. J. 50(3), 578-582.

Wildenschild, D., Hopmans, J.W., Vaz, C.M.P., Rivers, M.L., Rikard, D., Christensen, B.S.B., 2002. Using X-ray computed tomography in hydrology: Systems, resolutions, and limitations. Journal of Hydrology 267, 285-297.

Wooding, R., 1968. Steady infiltration from a shallow circular pond. Wat. Resourc. Res. 4, 1259-1273. 


\section{Figures}

Fig. 1. 3-D renderings of macropores ( $>0.147 \mathrm{~mm}$ ) obtained from X-ray Computed Tomography of the two soils for the three horizons.

Fig. 2. Unsaturated hydraulic conductivities of the two soils for (top) the topsoils, (middle) the upper subsoils, and (bottom) the lower subsoils. The bars denote the standard deviation of three replicates.

Fig. 3. Relationships of macroporosities (total macroporosity $(T M P(>0.147))$, connected total macroporosity $\left.\left(\operatorname{CTMP} P_{(} 0.147\right)\right)$, macroporosity between 0.75 and $3 \mathrm{~mm}\left(M P_{(3-0.75)}\right)$, and connected macroporosity between 0.75 and $\left.3 \mathrm{~mm}\left(C M P_{(3-0.75)}\right)\right)$ derived with $\mathrm{X}$-ray Computed Tomography and the unsaturated hydraulic conductivity determined in situ at $-10 \mathrm{~mm}$ ( $K_{\text {unsat }}$ $10 \mathrm{~mm})$ ) and $-40 \mathrm{~mm}\left(K_{\text {unsat }}(-40 \mathrm{~mm})\right)$ using tension-disc infiltrometry for the Andosol (a, c, e, g) and the Gleysol (b, $d, f, g)$. Solid lines represent linear relationships. The $R^{2}$ and $P$-values for the regressions are provided.

Fig. 4. Depth distribution of the limiting macroporosity $\left(T M P_{(>0.147)}\right)$ and the connected limiting macroporosity $\left(\operatorname{CTMP}_{(>0.147)}\right)$ for all soil cores of $(a, c)$ the Andosol and $(b, d)$ the Gleysol. Relationship of limiting $T M P_{(>0.147)}$ and the unsaturated hydraulic conductivity determined in situ at $-10 \mathrm{~mm}\left(K_{\text {unsat }}(-10 \mathrm{~mm})\right)$ using tension-disc infiltrometry for the Andosol (e) and the Gleysol (f). Solid lines represent linear relationships. The $R^{2}$ and $P-$ values for the regressions are provided. 


\section{Tables}

Table 1 Selected physical and chemical properties of the two soils and for the three horizons studied.

\begin{tabular}{lcccccc}
\hline \multirow{2}{*}{$\begin{array}{l}\text { Soil } \\
\text { Horizon }\end{array}$} & Ah & Bw1 & Bw2 & Ah & Bg1 & Bg2 \\
\cline { 2 - 7 } Depth (cm) & $0-15$ & $15-31$ & $31-64$ & $0-20$ & $20-38$ & $>38$ \\
\hline Sand (\%) & 24 & 19 & n.d..$^{\text {a }}$ & 10 & 0 & n.d. \\
Silt (\%) & 50 & 47 & n.d. & 38 & 31 & n.d. \\
Clay (\%) & 26 & 34 & n.d. & 52 & 69 & n.d. \\
Organic Carbon (\%) & 6.8 & 1.7 & n.d. & 5.4 & 0.8 & n.d. \\
Bulk density (g cm ${ }^{-3}$ ) & 0.8 & 0.8 & 0.8 & 0.9 & 1.1 & 1.0 \\
Total porosity (\%) & 65.5 & 70.7 & 71.8 & 63.8 & 60.8 & 61.5 \\
Macroporosity -10 kPa (\% vol.) & 11.8 & 22.8 & 25.4 & 1.7 & 6.7 & 1.8 \\
\hline
\end{tabular}

${ }^{a}$ n.d. not determined 
Table 2 The average macropore density $(M P D)$, macropore diameter (MPDIA, diameter of the connected macropores (CMPDIA), total X-ray CT Macroporosity $(T M P(>0.147))$, the connected total macroporosity $\left(C T M P_{(>0.147)}\right)$, the number of connected macropores, the genus density, and the vertical tortuosity for the two soils and three horizons. Standard error of three replicates in parentheses.

\begin{tabular}{|c|c|c|c|c|c|c|}
\hline \multirow{2}{*}{$\begin{array}{l}\text { Soil } \\
\text { Horizon }\end{array}$} & \multicolumn{3}{|c|}{ Andosol } & \multicolumn{3}{|c|}{ Gleysol } \\
\hline & $\mathrm{Ah}$ & Bw1 & Bw2 & Ah & Bg1 & $\mathrm{Bg} 2$ \\
\hline $\begin{array}{l}\text { MPD } \\
\text { (number } \mathrm{mm}^{-3} \text { ) }\end{array}$ & $\begin{array}{l}1.129 \\
(0.112)\end{array}$ & $\begin{array}{l}1.487 \\
(0.056)\end{array}$ & $\begin{array}{l}1.568 \\
(0.136)\end{array}$ & $\begin{array}{l}0.679 \\
(0.046)\end{array}$ & $\begin{array}{l}0.769 \\
(0.045)\end{array}$ & $\begin{array}{l}0.433 \\
(0.054)\end{array}$ \\
\hline $\begin{array}{l}\text { MPDIA } \\
(\mathrm{mm})\end{array}$ & $\begin{array}{l}0.272 \\
(0.004)\end{array}$ & $\begin{array}{l}0.237 \\
(0.002)\end{array}$ & $\begin{array}{l}0.222 \\
(0.004)\end{array}$ & $\begin{array}{l}0.378 \\
(0.013)\end{array}$ & $\begin{array}{l}0.278 \\
(0.005)\end{array}$ & $\begin{array}{l}0.288 \\
(0.002)\end{array}$ \\
\hline $\begin{array}{l}\text { CMPDIA } \\
(\mathrm{mm})\end{array}$ & $\begin{array}{l}0.300 \\
(0.010)\end{array}$ & $\begin{array}{l}0.301 \\
(0.008)\end{array}$ & $\begin{array}{l}0.266 \\
(0.013)\end{array}$ & $\begin{array}{l}0.390 \\
(0.019)\end{array}$ & $\begin{array}{l}0.297 \\
(0.008)\end{array}$ & $\begin{array}{l}0.306 \\
(0.003)\end{array}$ \\
\hline $\begin{array}{l}T M P_{(>0.147)} \\
\left(\mathrm{mm}^{3} \mathrm{~mm}^{-3}\right)\end{array}$ & $\begin{array}{l}0.065 \\
(0.004)\end{array}$ & $\begin{array}{l}0.035 \\
(0.003)\end{array}$ & $\begin{array}{l}0.034 \\
(0.002)\end{array}$ & $\begin{array}{l}0.141 \\
(0.027)\end{array}$ & $\begin{array}{l}0.069 \\
(0.004)\end{array}$ & $\begin{array}{l}0.049 \\
(0.005)\end{array}$ \\
\hline $\begin{array}{l}\operatorname{CTMP}_{(>0.147)} \\
\left(\mathrm{mm}^{3} \mathrm{~mm}^{-3}\right)\end{array}$ & $\begin{array}{l}0.048 \\
(0.006)\end{array}$ & $\begin{array}{l}0.011 \\
(0.002)\end{array}$ & $\begin{array}{l}0.007 \\
(0.002)\end{array}$ & $\begin{array}{l}0.133 \\
(0.027)\end{array}$ & $\begin{array}{l}0.054 \\
(0.006)\end{array}$ & $\begin{array}{l}0.039 \\
(0.004)\end{array}$ \\
\hline $\begin{array}{l}C T M P_{(>0.147)} \text { of } \\
T M P_{(>0.147)}(\%)\end{array}$ & 74 & 31 & 20 & 94 & 79 & 80 \\
\hline $\begin{array}{l}\text { Number of } \\
\text { connected } \\
\text { macropores (-) }\end{array}$ & 1 & 5 & 3 & 1 & 1 & 2 \\
\hline $\begin{array}{l}\text { Genus density } \\
\left(\mathrm{mm}^{-3}\right)\end{array}$ & $\begin{array}{l}1.022 \\
(0.018)\end{array}$ & $\begin{array}{l}0.200 \\
(0.030)\end{array}$ & $\begin{array}{l}0.223 \\
(0.031)\end{array}$ & $\begin{array}{l}1.507 \\
(0.393)\end{array}$ & $\begin{array}{l}0.548 \\
(0.051)\end{array}$ & $\begin{array}{l}0.353 \\
(0.026)\end{array}$ \\
\hline $\begin{array}{l}\text { Vertical } \\
\text { tortuosity (-) }\end{array}$ & $\begin{array}{l}2.615 \\
(0.024)\end{array}$ & $\begin{array}{l}2.815 \\
(0.014)\end{array}$ & $\begin{array}{l}2.709 \\
(0.016)\end{array}$ & $\begin{array}{l}2.996 \\
(0.020)\end{array}$ & $\begin{array}{l}3.098 \\
(0.025)\end{array}$ & $\begin{array}{l}3.366 \\
(0.112)\end{array}$ \\
\hline
\end{tabular}


Table 3 Pearson correlation coefficients among different macropore characteristics (log(macroporosity) C1; $\log$ (mean macropore diameter) C2; log(genus density) C3; vertical tortuosity C4; macropore density (5), as determined from X-ray computed tomographyimages and hydraulic parameters $\left(\log \left(K_{\text {unsat }}(-10 \mathrm{~mm}) \mathrm{C} 6\right.\right.$; and $\log \left(K_{\text {unsat }}(-70 \mathrm{~mm}) \mathrm{C}\right)$ for all horizons of the two soils studied. Probability values in parentheses are indicated by two significance levels $\left({ }^{* *}<0.01 ;{ }^{*}<0.05\right)$.

\begin{tabular}{lcccccc}
\hline & C1 & C2 & C3 & C4 & C5 & C6 \\
\hline & 0.919 & & & & & \\
C2 & $(<0.001)^{* *}$ & & & & & \\
& 0.934 & 0.818 & & & & \\
C3 & $(<0.001)^{* *}$ & $(<0.001)^{* *}$ & & & & \\
& 0.161 & 0.410 & -0.0219 & & & \\
C4 & $(<0.523)$ & $(0.091)$ & $(0.931)$ & & & \\
& -0.578 & -0.754 & -0.490 & -0.790 & & \\
C5 & $(0.0119)^{*}$ & $(0.0003)^{* *}$ & $(0.039)^{*}$ & $(<0.001)^{* *}$ & & \\
& 0.462 & 0.202 & 0.505 & -0.625 & 0.248 & \\
C6 & $(0.053)$ & $(0.422)$ & $(0.0325)^{*}$ & $(<0.001)^{* *}$ & $(0.322)$ & \\
& -0.594 & -0.808 & -0.429 & -0.640 & 0.777 & 0.216 \\
C7 & $(0.009)^{* *}$ & $(<0.001)^{* *}$ & $(0.075)$ & $(0.004)^{*}$ & $(<0.001)^{* *}$ & $(0.390)$ \\
\hline
\end{tabular}




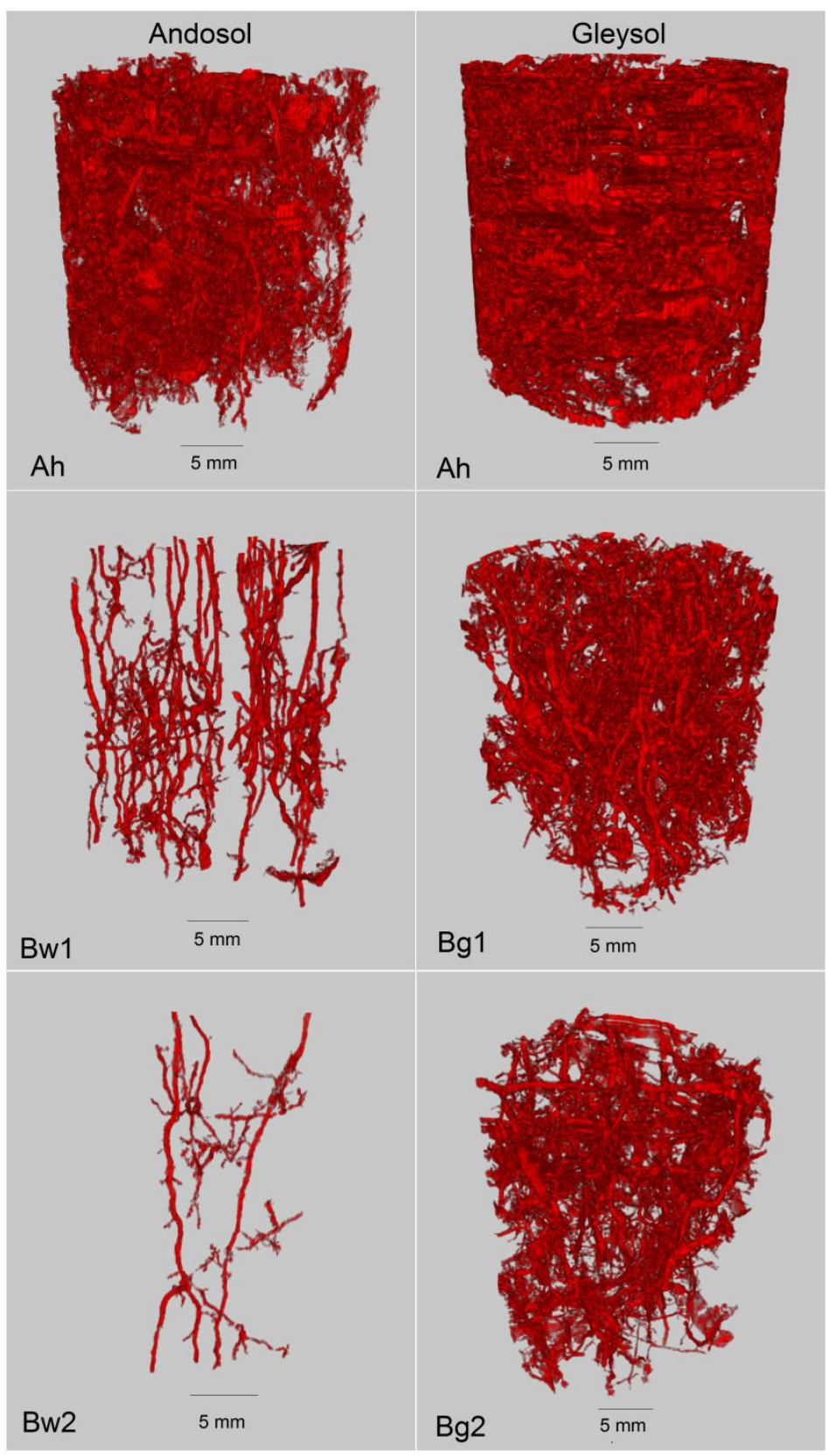



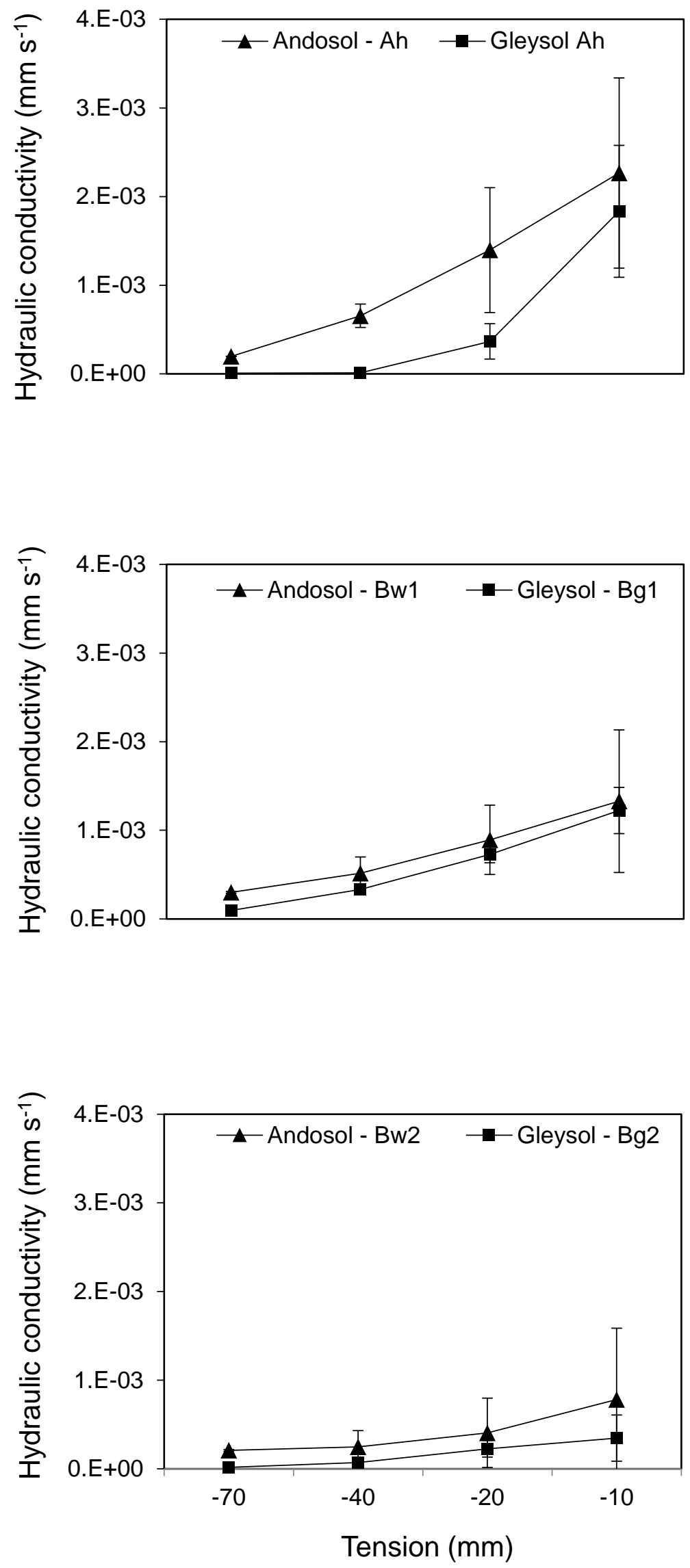

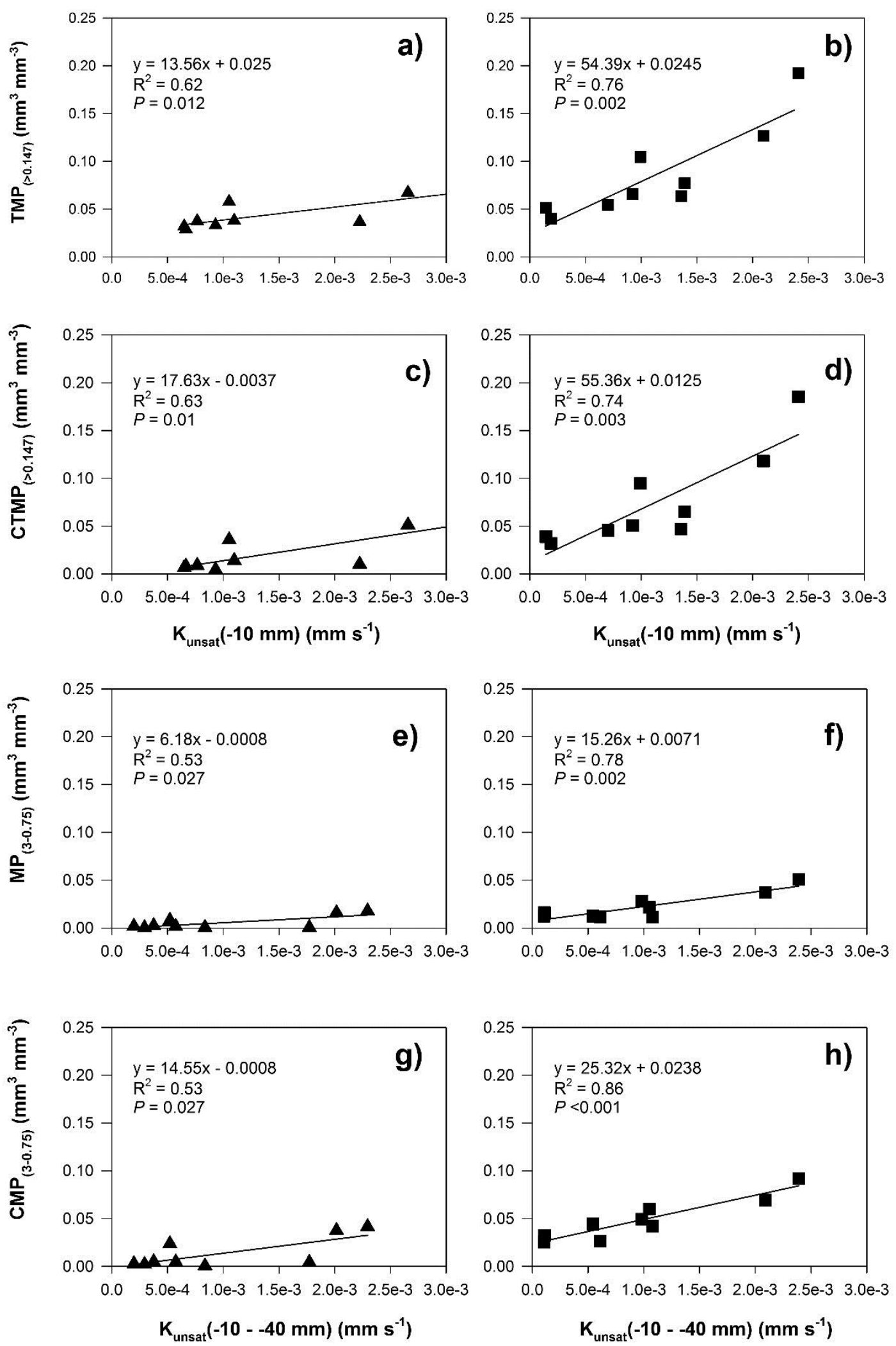

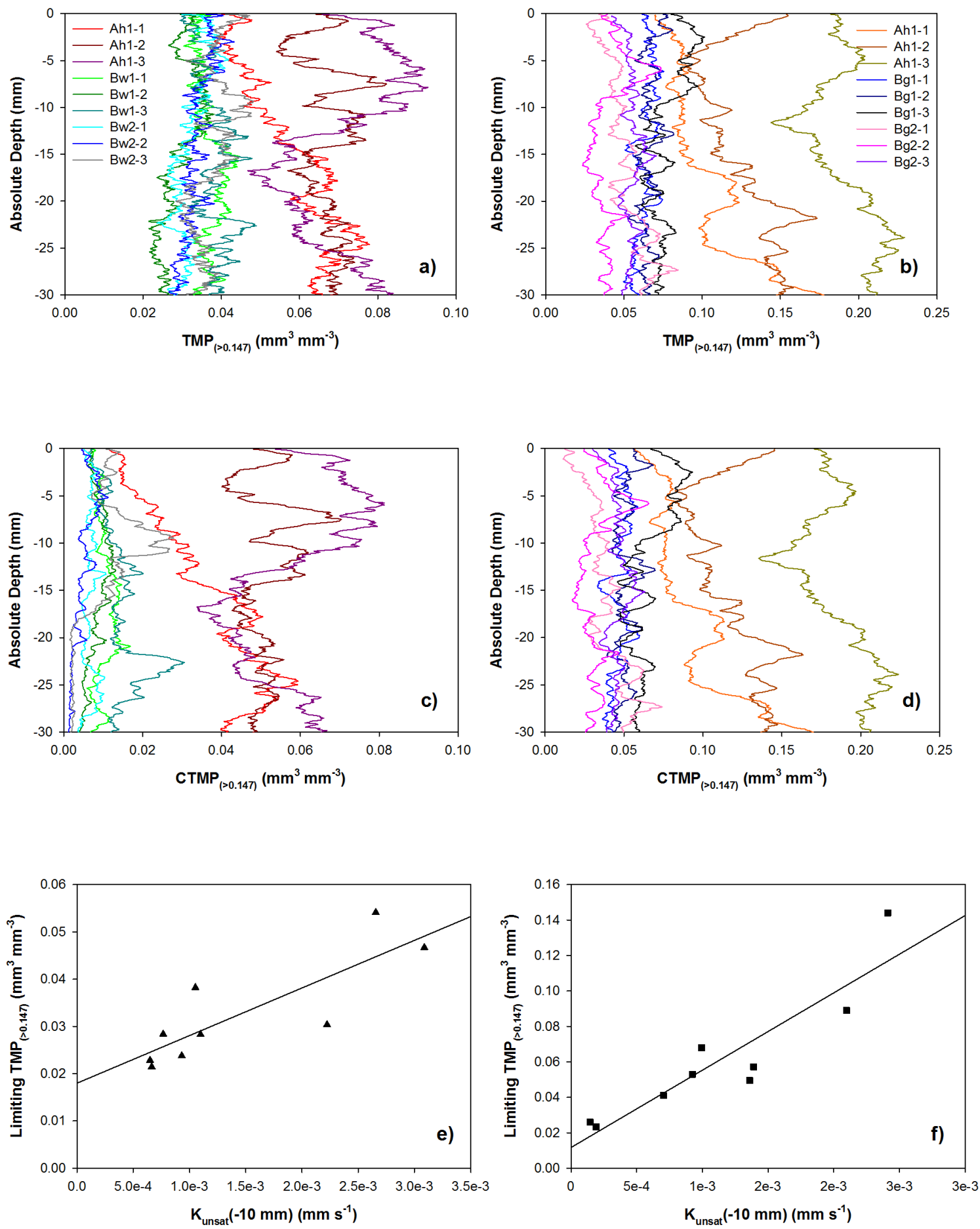